\title{
Acute Ischemic Stroke on Cancer Patients, a Distinct Etiology? A Case-Control Study
}

\author{
Acidente Vascular Cerebral Isquémico Agudo nos Pacientes com Cancro, uma \\ Etiologia Distinta? Estudo de Caso-Controlo
}

Ana Carrilho ROMEIRO $\rrbracket^{1}$, Anabela VALADAS ${ }^{1}$, José MARQUES ${ }^{1}$

Acta Med Port 2015 Sep-Oct;28(5):613-618

\section{ABSTRACT}

Introduction: It is still unclear whether the etiology of ischemic stroke differs between cancer and non-cancer patients. Stroke and cancer share common modifiable risk factors but evidence suggests that cancer patients have specific conditions that increase the risk of stroke. Our goal was to compare the etiology of ischemic stroke in cancer and non-cancer patients.

Material and Methods: Case-control study conducted in patients admitted to a stroke unit between January 2007 and December 2012. Cases had a concomitant diagnosis of cancer and acute ischemic stroke, controls of only stroke. Age, gender, vascular risk factors and etiology were compared between groups.

Results: Fifty-six cases were identified; $64.3 \%$ were men with a mean age of 71 years; 21 patients had evidence of active cancer. Gastrointestinal cancer (25.9\%) was the most common; 151 controls were included matched for gender and age. Common modifiable vascular risk factors, between groups (cases versus controls) were not significantly different, except for diabetes mellitus, more frequent in the control group $(16.1 \%$ vs $33.8 \%, p=0.02)$. Previous thrombotic events were more frequent in the cancer cohort $(8.9 \%$ vs $0.7 \%$, $p=0.007$ ). Other determined etiology subtype (TOAST classification) was more frequent in cancer patients when compared to controls $(13.0 \%$ vs $0.8 \%, p<0.01)$, and a hypercoagulable state was significantly more prevalent in active cancer patients.

Discussion: In our case-control study two subsets of cancer patients were delineated. In a subgroup, cancer and stroke co-exist, sharing traditional vascular risk factors. In another subset of patients, stroke appears to be directly related to the presence of a malignancy, where hypercoagulopathy turns out to be a decisive mechanism.

Conclusion: In clinical grounds, hypercoagulopathy as stroke etiology should prompt the physician to screen the patient for occult cancer.

Keywords: Neoplasms/etiology; Risk Factors; Stroke; Thrombophilia.

\section{RESUMO}

Introdução: Actualmente ainda não se encontra claramente definido se a etiologia do acidente vascular cerebral isquémico agudo difere entre doentes com e sem cancro. O acidente vascular cerebral isquémico e o cancro apresentam factores de risco comuns. No entanto, a literatura sugere que os doentes com cancro apresentam condições específicas que aumentam o risco de acidente vascular cerebral. O nosso objectivo foi comparar a etiologia do acidente vascular cerebral isquémico entre doentes com cancro e sem cancro. Material e Métodos: Estudo de caso-controlo realizado em doentes internados numa Unidade de acidente vascular cerebral entre Janeiro de 2007 e Dezembro de 2012. Os casos foram definidos como doentes com o diagnóstico concomitante de acidente vascular cerebral isquémico agudo e cancro; os controlos apenas com o diagnóstico de acidente vascular cerebral. Foram comparados entre os grupos: idade, género, factores de risco vasculares e etiologia do acidente vascular cerebral.

Resultados: Foram identificados 56 casos, $64,3 \%$ do género masculino, com idade média de 71 anos; 21 doentes apresentavam doença neoplásica activa. O cancro gastrointestinal $(25,9 \%)$ foi o mais frequente. Foram incluídos 151 controlos, emparelhados para a idade e género. A comparação dos factores de risco vasculares entre casos e controlos não revelou diferenças estatisticamente significativas, excepto para a diabetes mellitus, mais frequente no grupo de controlo $(16,1 \%$ vs $33,8 \%, p=0,02)$. A presença de história de eventos trombóticos prévios foi mais frequente na coorte de doentes com doença neoplásica $(8,9 \%$ vs $0,7 \%, p=0,007)$. O subtipo de etiologia do acidente vascular cerebral (classificação TOAST) 'outra etiologia' foi mais frequente nos doentes com cancro (13,04\% vs $0,83 \%, p<0,01$ ), e a presença de um estado pró-trombótico foi mais frequente nos doentes com neoplasia activa.

Discussão: Os resultados obtidos no nosso estudo permitiram definir dois subgrupos de casos. Num subgrupo de doentes, o cancro e o acidente vascular cerebral isquémico co-existiram e partilharam factores de risco. No segundo subgrupo de casos, o acidente vascular cerebral pareceu estar directamente relacionado com a doença neoplásica. O estado pró-trombótico constitui um mecanismo fundamental para a fisiopatogénese do acidente vascular cerebral isquémico.

Conclusão: Na práctica clínica, a identificação de hipercoagulabilidade como etiologia do acidente vascular cerebral deve alertar o médico para a pesquisa de uma doença neoplásica oculta.

Palavras-chave: Acidente Vascular Cerebral; Factores de Risco; Neoplasias/etiologia; Trombofilia.

\section{INTRODUCTION}

Cerebrovascular disease and cancer are both common disorders that share modifiable risk factors responsible for its occurrence, including smoking, obesity, physical inactivity and diet. Moreover, incidence of both conditions increases with age. ${ }^{1}$ In case of malignancy, incidence also

varies among racial groups and some organ-specific cancer is more common in determined world regions.

The association between ischemic stroke and cancer has long been studied, with changes on analysis approach over the years. The first clinical studies only evaluated

1. Serviço de Neurologia. Hospital de São Bernardo. Centro Hospitalar de Setúbal. Setúbal. Portugal.

$\triangle$ Autor correspondente: Ana Carrilho Romeiro. ana_carrilho@msn.com

Recebido: 02 de Janeiro de 2015 - Aceite: 14 de Julho de 2015 | Copyright @ Ordem dos Médicos 2015 
classical vascular risk factors, finding similarities between cancer and non-cancer patients. ${ }^{2-4}$ Reflecting deeper knowledge of pathophysiology, in addition to a broad spectrum of diagnostic methods, recent data analysis has moved from traditional risk factor analysis to the study of mechanisms though unique to malignancy. ${ }^{5-9}$ Despite the fact that 'cryptogenic' stroke is more common in cancer patients, ${ }^{10}$ recent publications suggest that ischemic stroke in those patients is distinctive by its association with hypercoagulability, a distinctive multiple lesion pattern on brain imaging and embolism. ${ }^{5-9,11}$ Such investigation approaches appear to indicate that multiple mechanisms are involved in ischemic stroke etiology in cancer patients, linking both pathologies. Nevertheless, it is still unclear whether the characteristics of ischemic stroke in cancer patients differ from non-cancer patients, turning out impossible to define in which cancer patient subgroup malignancy causes stroke more directly.

The purpose of this study was to compare the etiology of acute ischemic stroke in cancer and non-cancer patients, analysing not only common modifiable vascular risk factors but also cancer status, specifically cancer activity and cancer cell histology. With this dual approach, the authors wish to perform a careful integration of the traditional stroke risk factors and intrinsic cancer mechanisms.

\section{MATERIAL AND METHODS Study design}

Patients with a concomitant diagnosis of acute ischemic stroke and cancer (cases) admitted to our stroke unit, in a secondary referral hospital, between January 2007 and December 2012, were identified by reviewing data recorded prospectively on an electronic database. Patients were admitted from the emergency room. Patients with acute ischemic stroke with imaging evidence of brain infarct were eligible for the study. Exclusion criteria included presence of hemorrhagic stroke, venous cerebral thrombosis, transitory ischemic attack (TIA), primary cerebral neoplasm and cerebral metastases, and absence of signs suggesting ischemic stroke on brain imaging. The diagnosis of ischemic stroke was made independently by at least one stroke unit neurologist. For comparison purposes, patients with acute ischemic stroke and without history of cancer were randomly selected as controls (non-cancer patients), with admission on stroke unit during the same time period and matched for age and gender. Collected data for both study groups included: age, gender, patients' medical history and regular medication, common modifiable vascular risk factors for stroke (hypertension, atrial fibrillation, diabetes mellitus, coronary vessel disease, smoking, dyslipidemia and previous ischemic stroke/TIA). A previous history of thrombotic events (deep vein thrombosis and pulmonary embolism) was also recorded. Routine evaluation in all stroke patients included serial neurological and physical examination, cerebral tomography scan (brain CT scan), electrocardiogram, transthoracic echocardiogram, carotid duplex and laboratory tests (hematology, biochemistry and coagulation parameters). Blood samples were collected during the first 24 hours after the onset of stroke and in cases submitted to intravenous fibrinolysis, previous to that treatment. Brain magnetic resonance imaging (MRI), Holter, transesophagic echocardiogram, other coagulation data besides prothrombin time (PT, seconds), PT international normalized ratio (PT-INR) and activated thromboplastin time (aPTT, seconds) were performed only if necessary on a case by case basis. D-dimer cut-off level for the Hospital laboratory was equal or less than $250 \mathrm{ng} / \mathrm{mL}$.

\section{Cancer status characterization}

Cancer diagnosis was based on clinical, laboratory, imaging and histological examinations. The primary location was determined using medical and imaging data. According to the pathological analysis of cancer tissue specimens, histology was categorized into adenocarcinoma or nonadenocarcinoma. Cancer staging was classified according to the TNM classification system into three categories: in situ and/or organ limited without lymph node metastases (stage I), extensive disease but without systemic metastases (stage II, III) and systemic disease with evidence of spreading to distant tissues or organs (stage IV). Patients with malignancy diagnosis within six months before hospitalization or during stroke hospitalization, with any neoplastic treatment within the previous six months or with systemic malignancy (stage IV) were defined as active cancer patients. Cancer treatment included surgery, chemotherapy, radiotherapy, hormone therapy, combined therapy and no treatment. The interval from time of cancer diagnosis to occurrence of the index cerebral ischemic event was stratified: during hospitalization or after discharge (less than three months, 3 to 6 months, 6 to 12 months, more than 12 months).

\section{Stroke etiology subtypes}

Acute ischemic stroke etiology was designated at patient discharge, from the Trial of ORG 10172 in Acute Stroke Treatment (TOAST) Study, ${ }^{12}$ which divides it into five categories: large-artery atherosclerosis (embolus/ thrombosis); cardioembolism; small-vessel occlusion; stroke of other determined etiology (nonatherosclerotic vasculopathies, hypercoagulable states or hematologic disorders) and stroke of undetermined etiology (two or more causes identified, negative evaluation, incomplete evaluation). Hypercoagulable state was evaluated retrospectively based on coagulation parameters and D-dimer levels.

\section{Statistical analysis}

Statistical analysis was undertaken using the software $\mathrm{R}$ (R-3.0.2, http://www.r-project.org/). Analysis of differences in the frequency of categorical variables was performed using the Chi-square test. The Mann-Whitney $U$ test was used to compare ordinal data between cancer and noncancer patients. The reported $p$ values are the results of twosided tests. A $p$-value $<0.05$ was considered statistically significant. 


\section{RESULTS}

\section{Baseline and vascular risk profile characterization}

Fifty-six patients with concomitant diagnosis of cancer and acute ischemic stroke were identified as cases. Cancer patients had a mean age of 71 years (range 31-92 years) and $64.3 \%$ were men (Table 1 ).

Hypertension and dyslipidemia were the most common classical vascular risk factors for cancer patients as well as for controls. The frequency of vascular risk factors was similar between groups, except for diabetes mellitus, which was more frequent in the control group $(16.1 \%$ vs $33.8 \%$, $p=0.02$ ), (Table 1). Previous thrombotic events (deep vein thrombosis or pulmonary embolism) were significantly higher in cancer patients, present in 5 of 56 patients $(8.9 \%)$, when compared with controls ( $n=1,0.7 \%)$.

Classical vascular risk factors were not significantly different among cancer patients, according to cancer activity (active versus non-active cancer), but hypertension and dyslipidemia were significantly more frequent in patients with an adenocarcinoma when compared to those with a non-adenocarcinoma (Table 2).

\section{Cancer status analysis}

Gastrointestinal (25.9\%) and prostate (15.5\%) cancers were the most frequent primary tumor location among cases. Two patients had two distinct primary tumours simultaneously (Table 3). Thirty cancer patients showed histological evidence of an adenocarcinoma (50.8\%, Table
$3)$, with a primary origin in prostate $(\mathrm{n}=9,30 \%)$, colon/ rectum $(n=8,26.7 \%)$, breast $(n=8,26.7 \%)$, endometrium ( $n=2,6.7 \%)$, lung $(n=2,6.7 \%)$ and pancreas $(n=1,3.3 \%)$. Cancer stage was evaluated in all cases, with the majority of patients having an extensive or systemic malignancy (stages II, III and IV, 58.9\%) at the time of stroke admission. Malignancy was considered active in $37.5 \%$ of the cases ( $n=21), 11(52.3 \%)$ of which had an adenocarcinoma. Nevertheless, cancer activity was not significantly different according to cancer histology (adenocarcinoma 36.6\% vs non adenocarcinoma $38.5 \%$ ). At the time of stroke, 52 $(92.9 \%)$ cancer patients had been submitted to cancer specific therapy (Table 3). Five patients (8.93\%) were diagnosed with cancer during stroke hospitalization, 19 (33.93\%) had a stroke within one year after malignancy diagnosis and $32(57.15 \%)$ had a cancer diagnosis with more than 12 months (Table 3).

\section{Differences in stroke etiology}

For the definition of stroke etiology, besides the initial standard evaluation, brain MRI was performed in 6 of the 56 cancer patients $(10.7 \%)$ and in 21 of the 151 control patients $(13.9 \%)$. D-dimers were evaluated at the time of hospital admission in 13 cancer patients $(23.2 \%)$ and in 9 non-cancer patients $(6 \%)$.

Stroke etiological subtype 'cardioembolism' was the most frequent in both cancer patients $(n=17,30.4 \%)$ and controls ( $n=55,36.4 \%)$. The subtype 'other determined

Table 1 - Baseline characterization: demographics, common modifiable vascular risk factors and previous thrombotic events

\begin{tabular}{|c|c|c|c|}
\hline & Cancer patients, n (\%) & Controls, n (\%) & $p$ value \\
\hline n (patient number) & 56 & 151 & N.A. \\
\hline Age (years) & $70.95 \pm 10.4$ & $71.56 \pm 9.7$ & N.A. \\
\hline Gender (male) & $36(64.29)$ & $94(62.25)$ & N.A. \\
\hline \multicolumn{4}{|l|}{ Vascular risk factors } \\
\hline None & $4(7.14)$ & $6(3.97)$ & N.S. \\
\hline Hypertension & 40 (71.43) & $120(79.47)$ & N.S. \\
\hline Atrial fibrillation & $17(30.36)$ & 35 (23.18) & N.S. \\
\hline Diabetes mellitus* & $9(16.07)$ & $51(33.77)$ & $<0.05$ \\
\hline Coronary vessel disease & $6(10.71)$ & $19(12.58)$ & N.S. \\
\hline Smoking & $11(19.64)$ & $29(19.21)$ & N.S. \\
\hline Dyslipidemia & 22 (39.29) & $80(52.98)$ & N.S. \\
\hline Previous stroke/TIA & $5(8.93)$ & $15(9.93)$ & N.S. \\
\hline Previous thrombotic events* & $5(8.93)$ & $1(0.66)$ & $<0.05$ \\
\hline
\end{tabular}

${ }^{*}$ Statistically significant difference $(p<0.05)$; N.A.: Not applicable; TIA: Transitory ischaemic accident; N.S.: Not significant.

Table 2 - Comparison of common modifiable vascular risk factors on in the cancer cohort, according to cancer histology

\begin{tabular}{|c|c|c|c|}
\hline Common modifiable vascular risk factor & Adenocarcinoma, n (\%) & Non-adenocarcinoma, $\mathbf{n}(\%)$ & $p$ value \\
\hline None & $0(0)$ & 4 (15.4) & N.S. \\
\hline Hypertension* & $26(86.7)$ & $15(57.7)$ & $<0.05$ \\
\hline Atrial fibrillation & $12(40)$ & $6(23.1)$ & N.S \\
\hline Diabetes mellitus & $5(16.7)$ & $4(15.4)$ & N.S. \\
\hline Coronary vessel disease & $6(20)$ & $1(3.8)$ & N.S. \\
\hline Smoking* & $2(6.6)$ & $8(30.8)$ & $<0.05$ \\
\hline Dyslipidemia * & $16(53.3)$ & $6(23.1)$ & $<0.05$ \\
\hline Previous stroke/TIA & $3(10)$ & $2(7.7)$ & N.S. \\
\hline
\end{tabular}


Table 3 - Cancer status cohort characterization: tumour primary location, cell histology, stage and activity, interval from time of cancer diagnosis to occurrence of acute cerebral ischemic event

\begin{tabular}{|c|c|}
\hline Cancer Primary location* & $\mathrm{n}(\%)$ \\
\hline Gastrointestinal (GI) & $15(25.9)$ \\
\hline Prostate & $9(15.5)$ \\
\hline Bladder & $8(13.8)$ \\
\hline Breast & $8(13.8)$ \\
\hline Skin & $5(8.6)$ \\
\hline Hematological & $4(6.9)$ \\
\hline Lung & $4(6.9)$ \\
\hline Head and neck & $2(3.4)$ \\
\hline Endometrial & $2(3.4)$ \\
\hline Renal & $1(1.7)$ \\
\hline Stage & $\mathrm{N}(\%)$ \\
\hline In situ disease (I) & $9(16.07)$ \\
\hline Extensive disease (II, III) & 19 (33.93) \\
\hline Systemic disease (IV) & $14(25)$ \\
\hline Remission & $14(25)$ \\
\hline Cancer activity & $\mathrm{n}(\%)$ \\
\hline Active & $21(37.5)$ \\
\hline Non-active & $35(62.5)$ \\
\hline Cancer treatment & $\mathrm{n}(\%)$ \\
\hline Surgery & $22(39.3)$ \\
\hline Surgery and chemotherapy/radiotherapy & $15(26.8)$ \\
\hline Chemotherapy and/or radiotherapy & $11(19.7)$ \\
\hline Hormonotherapy and combined therapy & $4(7.1)$ \\
\hline None & $4(7.1)$ \\
\hline Time between cancer diagnosis and index event & $\mathrm{N}(\%)$ \\
\hline Less than 3 months & $6(10.71)$ \\
\hline 3 to 6 months & $6(10.71)$ \\
\hline 6 to 12 months & $12(21.43)$ \\
\hline More than 12 months & 32 (57.15) \\
\hline
\end{tabular}

etiology' was significantly more prevalent within cases ( $\mathrm{n}=10,17.9 \%$ vs $\mathrm{n}=1,0.7 \%, p<0.001$ ) (Table 3 ). All patients categorized as 'stroke of other determined etiology' had an initial D-dimer serum level evaluation. D-dimer concentration was significantly superior in cancer patients (cases mean value $1167.9 \mathrm{ng} / \mathrm{mL}$ vs controls mean value $381.5 \mathrm{ng} / \mathrm{mL}, p=0.0455$, Z-score 2.0033). In the cancer cohort, 10 of the 11 patients with stroke of other determined cause had a D-dimer concentration superior to $250 \mathrm{ng} / \mathrm{mL}$ (Fig. 1), and the presence of a hypercoagulable state was considered. Stroke etiology was indetermined in $19.6 \%$ of cancer patients (Table 4).

In patients with active cancer, the etiological subtype 'small vessel occlusion' was not present (0\% vs $25.71 \%$, $p=0.030$ ) and a hypercoagulable state ('other determined etiology') was significantly more prevalent than in non-active cancer patients ( $\mathrm{n}=8,38.1 \%$ vs $\mathrm{n}=3,8.57 \%, p=0.019$ ) (Table 5). No significant differences were found in TOAST subtypes according to cancer histology (adenocarcinoma versus non adenocarcinoma).

\section{DISCUSSION}

There are conspicuous differences in cancer epidemiology in different world regions. ${ }^{13}$ This study is to our knowledge the first to compare vascular risk factors and ischemic stroke etiology in Southern Europe with a control group. We found that cancer patients with acute ischemic stroke (1) have significantly less diabetes than non-cancer patients, (2) have gastrointestinal and prostate organs as the most common primary malignancy location, and (3) have significantly higher frequency of 'other determined' (TOAST) stroke etiology subtype.

The first studies reported similar prevalence of classical vascular risk factors between cancer and noncancer patients with acute ischemic stroke..$^{2-4,14}$ However, a recent German study ${ }^{7}$ showed that hyperlipidemia and

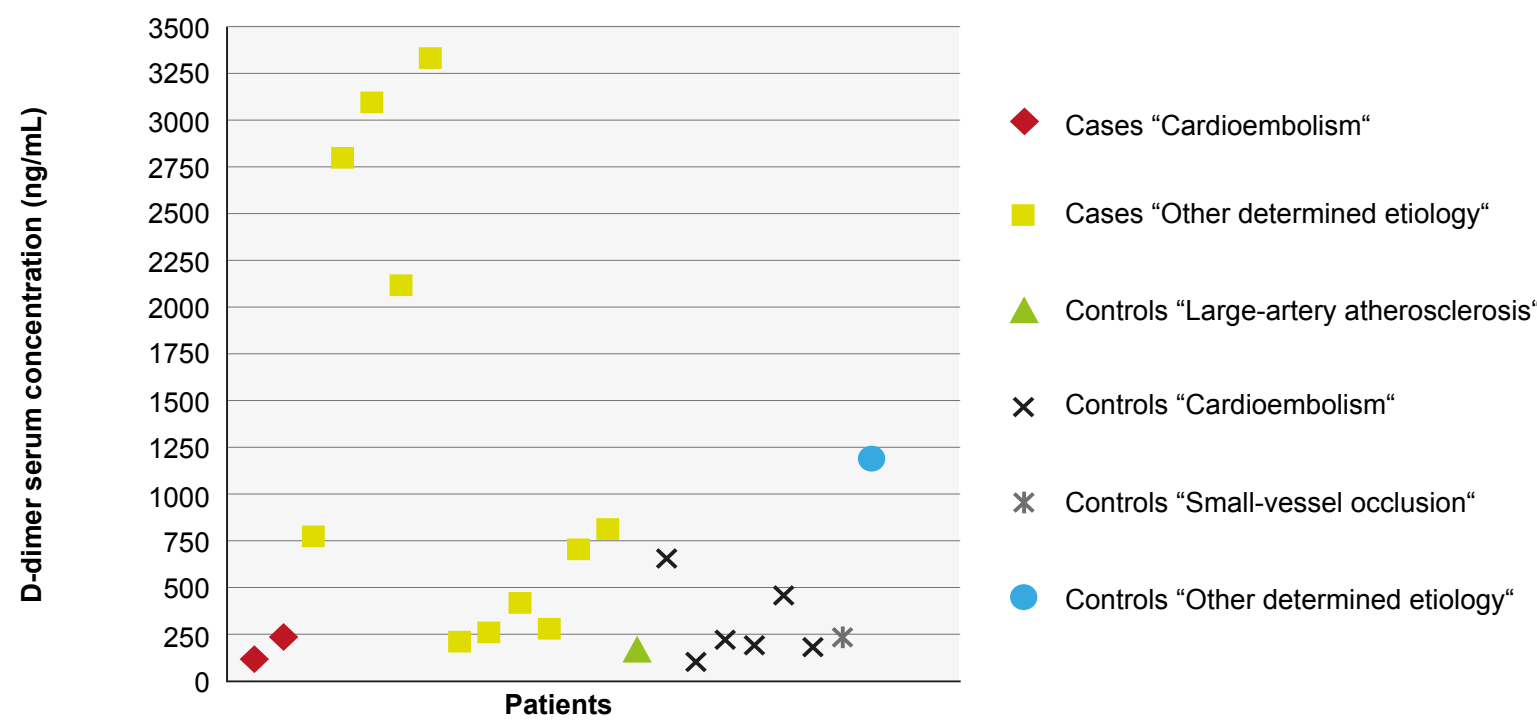

Figure 1 - D-dimer serum concentration at admission* in cancer and non-cancer patients, according to stroke aetiology (TOAST classification).

*significantly different between cases and controls, $p=0.045$, Z-score 2.0 
Table 4 - Stroke etiology characterization in cancer patients versus controls, according to TOAST classification

\begin{tabular}{|c|c|c|c|}
\hline Etiology & Cancer patients, $\mathbf{n}(\%)$ & Controls, n (\%) & $p$ value \\
\hline Large-artery atherosclerosis & $8(14.24)$ & $35(23.18)$ & N.S. \\
\hline Cardioembolism & $17(30.36)$ & $55(36.42)$ & N.S. \\
\hline Small vessel occlusion & $9(16.07)$ & $32(21.19)$ & N.S. \\
\hline Other & $11(19.64)$ & $1(0.66)$ & $<0.001$ \\
\hline Unknown & $11(19.64)$ & $28(18.54)$ & N.S. \\
\hline
\end{tabular}

Table 5 - Stroke etiology characterization in active cancer patients versus non active cancer patients, according to TOAST classification

\begin{tabular}{llcl}
\hline Aetiology & Active Cancer patients, $\mathbf{n}(\%)$ & Non active Cancer, $\mathbf{n}(\%)$ & $\boldsymbol{p}$ value \\
\hline Large-artery atherosclerosis & $2(9.52)$ & $6(17.14)$ & N.S. \\
Cardioembolism & $5(23.51)$ & $12(34.29)$ & N.S. \\
Small vessel occlusion & $0(0)$ & $9(25.71)$ & $<\mathbf{0 . 0 5}$ \\
Other & $8(38.09)$ & $3(8.57)$ & $<0.05$ \\
Unknown & $6(28.57)$ & $5(14.29)$ & N.S. \\
\hline
\end{tabular}

hypertension were less prevalent among cancer patients with no differences concerning diabetes, when compared with controls. Additionally, in a Korean retrospective study, ${ }^{8}$ classical vascular risk factors were less prevalent in active cancer patients. A recent prospective study also emphasizes the role of cancer activity in vascular profile distinction between cancer and non-cancer patients. ${ }^{15}$ On the other hand, another recent study, The Bergen NORSTROKE Study ${ }^{16}$ identified that patients with ischemic stroke and a previous history of cancer had a higher frequency of specific vascular risk factors (atrial fibrillation, heart disease and smoking), highlighting the fact that cancer and stroke have common risk factors. In our series of patients, there were no differences concerning vascular profile between active and non-active cancer patients, which could be explained by the limited number of patients with an active malignancy.

In one of the first reported studies, ${ }^{2}$ lung cancer was identified as the most common neoplasm in patients with stroke. Case series from Asia, ${ }^{6,8,9}$ reported gastric cancer as the most common malignancy, which is also one of the most frequent in the general Korean population. In the published Norway population study, ${ }^{16}$ colorectal was the most common cancer. These differences may be explained by distinct geographical cancer prevalence, but also different study design.

However, in the recent literature, lung and pancreatic cancer were overrepresented in cancer patients with ischemic stroke ${ }^{7}$ and cancer histology differed between the active cancer patients and patients with inactive malignancy, with adenocarcinoma type more often diagnosed in active disease. ${ }^{8,9}$ Furthermore, one of the stroke etiology cancer-related mechanisms proposed is explained by the expression of mucin-secreting tumour procoagulants, ${ }^{19}$ for which adenocarcinoma histology is frequently linked. ${ }^{10}$ In one of the few studies with histological analysis ${ }^{8}$ patients with active cancers had more frequently adenocarcinoma, a difference we did not find in our case series.

Reports on the characterization of stroke mechanism in cancer patients have shown discrepancies. Cestari et $\mathrm{al}^{2}$ found that embolism other than cardioembolism (e.g. infectious endocarditis, nonbacterial thrombotic endocarditis) was the most common cause of ischemic stroke in cancer patients. The first case-control report published $^{14}$ identified cardioembolism as the most common cause of ischemic stroke in cancer patients, but with no significantly differences between cancer and non-cancer patients. Other retrospective studies ${ }^{3,17}$ revealed that large-vessel atherosclerosis was the most frequent stroke etiological subtype, but also with no statistically differences between cancer and non-cancer groups. More recently, Lee et $\mathrm{al}^{8}$ identified large artery atherosclerosis as the most frequent etiology in cancer patients, but cryptogenic stroke subtype was more frequent in active cancer patients, which included not only stroke of undetermined etiology, but also cancer-related coagulopathy. In the largest North European case-control study, ${ }^{7}$ unidentified stroke etiology was significantly more frequent in the cancer group. Our study revealed that 'cardioembolism' was the stroke etiology subtype more common in cases, but not distinctive from non-cancer patients. Moreover, the TOAST subtype 'other determined etiology', specifically the presence of a hypercoagulable state, was more frequent in cancer patients, which was even more notorious if active malignancy. Those differences might partially be explained by different stroke etiology classifications used (TOAST, modified TOAST and ASCO system). Also, the search for embolism (echocardiography) and evaluation of D-dimers was not proportional in all studies.

The attribution of hypercoagulability as the causative mechanism for ischemic stroke in cancer patients is challenging, even though it is considered one of the several cancer associated risk factors for stroke.4,18,19 There is still no consensus of its relative importance compared with classical risk factors ${ }^{20}$ and the lack of specificity and sensitivity of coagulation markers, such as D-dimer levels, should be kept in mind. ${ }^{7}$ The recent literature ${ }^{5,7,8,19,21,22}$ reports 
significantly higher levels of D-dimers in cancer patients, especially in those with active malignancy ${ }^{8,22}$ and metastatic disease. ${ }^{7}$ In our study, D-dimers were higher in the cancer cohort and most patients had extensive or systemic disease, although these findings have to be interpreted with caution as the majority of patients did not have an evaluation of fibrin degradation products. Besides, recently a group found an independent association between elevated D-dimer levels and the prevalence of multiple embolic signals on transcranial Doppler on cancer patients with acute ischemic stroke, especially in those without conventional stroke mechanisms. ${ }^{20}$ Those results are suggestive of intravascular clot formation as one of the sources of embolism in cancer patients and should be studied in further prospective larger population studies.

The main limitations of this study include the small sample size, the monocentric design and the lack of D-dimer and fibrinogen assessments in some patients. Still, this is to our knowledge the first study to compare vascular risk factors and ischemic stroke etiology in Southern Europe using a control group, and our results could promote future larger studies.

\section{CONCLUSION}

Our study delineated two subsets of cancer patients with stroke. In a subgroup, both conditions co-exist, sharing

\section{REFERENCES}

1. Kamangar F, Dores GM, Anderson WF. Patterns of cancer incidence, mortality, and prevalence across five continents: Defining priorities to reduce cancer disparities in different geographic regions of the world. $J$ Clin Oncol. 2006;4:2137.

2. Cestari DM, Weine DM, Panageas KS, Segal AZ, DeAngelis LM. Stroke in patients with cancer: incidence and aetiology. Neurology. 2004;62:2025-30.

3. Oberndorfer S, Vera N, Otto B, Heinz L, Wolfgang G. Stroke in cancer patients: a risk factor analysis. J Neuroonco. 2009;94:221-6.

4. Grisold W, Oberndorfer S, Struhal W. Stroke and cancer: a review. Acta Neurol Scand. 2009;119:1-16.

5. Kim SJ, Park JH, Lee MJ, Park YG, Ahn MJ, Bang OY. Clues to occult cancer in patients with ischemic stroke. PLoS One. 2012;7:e44959.

6. Kim SG, Hong JM, Kim HY, Lee J, Chung PW, Park KY, et al. Ischaemic stroke in cancer patients with and without conventional mechanisms: a multicentre study in Korea. Stroke. 2010;41:798-801.

7. Schwarzbach CJ, Schaefer A, Ebert A, Held V, Bolognese M, Kablau $\mathrm{M}$, et al, Stroke and Cancer: The importance of Cancer-Associated Hypercoagulation as a Possible Stroke Aetiology. Stroke, 2012;43:30293034.

8. Lee EJ, Nah HW, Kwon JY, Kang DW, Kwon SU, Kim JS. Ischaemic Stroke in patients with cancer: is it different from usual strokes? Int $J$ Stroke. 2014;9:406-12

9. Kim JM, Jung KH, Park KH, Lee ST, Chu K, Roh JK. Clinical manifestation of cancer related stroke: retrospective case-control study. J Neurooncol. 2013;111:295-301.

10. Dearbon JL, Urrutia VC, Zeiler SR. Stroke and cancer- a complicated relationship. J Neurol TransI Neurosci. 2014;2:1039.

11. Bang OY, Seok JM, Kim SG, Hong JM, Kim HY, Lee J, et al. Ischaemic stroke and cancer: Stroke severely impacts cancer patients, while cancer increases the number of strokes. J Clin Neurol. 2011;7:53-59.

12. Adams HP, Bendixen BH, Kappelle LJ, Biller J, Love BB, Gordon DL, et traditional vascular risk factors. More importantly, in another subset of patients, stroke appears to be directly related to the presence of a malignancy, where hypercoagulopathy turns out to be a decisive mechanism. In clinical grounds, whenever stroke occurs in the setting of a hypercoagulable state, physicians must be aware that occult cancer is a possibility, with future potential implications on the approach of acute ischemic stroke, including intravenous fibrinolysis and secondary prevention.

\section{PROTECTION OF HUMANS AND ANIMALS}

The authors declare that the procedures were followed according to the regulations established by the Clinical Research and Ethics Committee and to the Helsinki Declaration of the World Medical Association.

\section{DATA CONFIDENTIALITY}

The authors declare having followed the protocols in use at their working center regarding patient's data publication.

\section{CONFLICTS OF INTEREST}

The authors declare that they have no conflicts of interest with regard to this study.

\section{FUNDING SOURCES}

No subsidies or grants contributed to this work.

al. Classification of subtype of acute ischemic stroke definitions for use in a multicenter clinical trial. TOAST. Trial of Org 10172 in Acute Stroke Treatment. Stroke. 1993;24:35-41.

13. Parkin DM, Bray F, Ferlay J, Pisani P. Global cancer statistics, 2002. CA Cancer J Clin. 2005;55:74-108.

14. Zhang YY, Cordato D, Shen $Q$, Sheng AZ, Hung WT, Chan DKY. Risk factor, pattern, aetiology and outcome in ischaemic stroke patients with cancer: a nested case-control study. Cerebrovasc Dis. 2007;23:181-7.

15. Karlinska AG, Gromadzka G, Karlinski MA, Czlonkowska A. The activity of malignancy may determine stroke pattern in cancer patients. J Stroke Cerebrovasc Dis. 2015;24:778-83.

16. Selvik HA, Thomassen L, Logallo N, Næss H. Prior cancer in patients with ischemic stroke: the Bergen NORSTROKE study. J Stroke Cerebrovasc Dis. 2014;23:919-25.

17. Seok JM, Kim SG, Kim JW, Chung CS, Kim GM, Lee KH, et al Coagulopathy and embolic signal in cancer patients with ischaemic stroke. Ann Neurol. 2010;68:213-9.

18. Chaturvedi S, Ansell J, Recht L. Should cerebral ischemic events in cancer patients be considered a manifestation of hypercoagulability? Stroke. 1994;25:1215-8.

19. Buccheri G, Torchio P, Ferrigno D. Plasma levels of D-dimer in lung carcinoma - clinical and prognostic significance. Cancer. 2003;97:304452.

20. Kono T, Ohtsuki T, Hosomi N, Takeda I, Aoki S, Sueda Y, et al. Cancerassociated ischaemic stroke is associated with elevated D-dimer and fibrin degradation product levels in acute ischaemic stroke with advanced cancer. Geriatr Gerontol Int. 2012:468-74.

21. Haller S, Lyrer P. Malignancy and stroke. Semin Cerebrovasc Dis Stroke. 2005;5:47-54.

22. Guo YJ, Chang MH, Chen PL, Lee YS, Chang YC, Liao YC. Predictive value of plasma D-dimer levels for cancer-related stroke: a 3-year retrospective study. J Stroke Cerebrovasc Dis. 2014;23:e249-54. 
Ana Carrilho ROMEIRO, Anabela VALADAS, José MARQUES

\section{Acute Ischemic Stroke on Cancer Patients, a Distinct Etiology? A Case-Control Study}

Acta Med Port 2015:28:613-618

Publicado pela Acta Médica Portuguesa, a Revista Científica da Ordem dos Médicos

Av. Almirante Gago Coutinho, 151

1749-084 Lisboa, Portugal.

Tel: +351218428 215

E-mail: submissao@actamedicaportuguesa.com

www.actamedicaportuguesa.com

ISSN:0870-399X | e-ISSN: 1646-0758

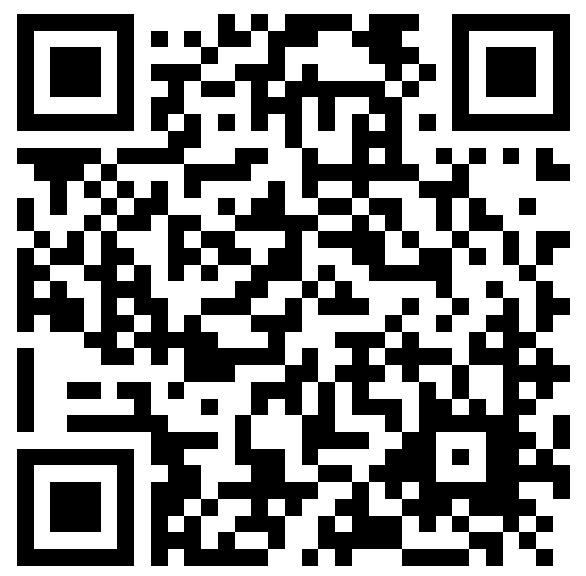

